\title{
La determinación de la habitualidad en el delito de maltrato habitual (artículo 173.3 Código Penal Español)*
}

\author{
Natalia Pérez Rivas*
}

Recibido: agosto de 2015

Aprobado: julio de 2016

DOI: 10.22395/ojum.v15n30a8

\section{RESUMEN}

La habitualidad se configuraba como el elemento esencial del delito de maltrato habitual (artículo 173.3 CP). Pese a ello, no se contiene, en el Código Penal español, una definición de lo que ha de entenderse por habitualidad. El legislador se ha limitado a fijar los criterios que deben ser tomados en consideración por el órgano judicial para apreciar su concurrencia. Pues bien, la finalidad de este artículo es el análisis de esos criterios a efectos de aportar los elementos materiales con los que dar contenido a cada uno de ellos. Para ello hemos tomado en consideración no solo las opiniones doctrinales y la jurisprudencia existente al respecto, sino también los datos extraídos de los expedientes de la Fiscalía de Santiago de Compostela (Galicia, España), relativos a asuntos sobre violencia de género y que concluyeron con sentencia firme, por delito de maltrato habitual, durante los años 2005 a 2012.

Palabras clave: violencia doméstica; delito de maltrato habitual; habitualidad.

\footnotetext{
El presente trabajo se inscribe en el marco del Proyecto de Investigación financiado por el Ministerio de Economía y competitividad (FEM 2010-22350-C02-02) "La violencia de género: problemas de calificación jurídico-penal", en el que he participado como investigadora. El proyecto de inició el 1 de enero de 2010 y finalizó el 31 de diciembre de 2013.

* Licenciada y doctora en Derecho por la Universidad de Santiago de Compostela (España). Licenciada en Criminología por la Universidad de Alicante (España). Profesora de Derecho Penal y Criminología, Universidad de Santiago de Compostela (España). Correo electrónico: natalia.perez.rivas@usc.es.
} 


\section{Determining the Habitual Practice of Abuse (Article 173.3, Spanish Criminal Code)}

\section{ABSTRACT}

Habitual practice was seen as the essential element of the crime of habitual abuse (Article 173.3, Criminal Code). However, the Spanish Criminal Code does not contain a definition on what should be understood as habitual practice. The legal system has been restricted to set the criteria to be taken into consideration by the legal system to consider its concurrence. The purpose of this article is to analyze such criteria in order to provide necessary material elements to give meaning to such criteria. For this purpose, the article has not only taken the doctrinal opinions and the existing jurisprudence into consideration, but also the data taken from the files kept by Santiago de Compostela Prosecutor's Office in Galicia (Spain), in relation to issues on gender violence that ended up in a final verdict for the crime of habitual abuse between 2005 and 2012.

Key words: domestic violence; habitual abuse; habitual practice. 


\section{INTRODUCCIÓN}

La LO 3/1989, de 21 de junio, introdujo, en el Texto Refundido del Código Penal español de 1973, la regulación del delito de maltrato habitual disponiendo que el que habitualmente, y con cualquier fin, ejerza violencia física sobre su cónyuge o persona a la que estuviese unido por análoga relación de afectividad, así como sobre los hijos sujetos a la patria potestad, o pupilo, menor o incapaz sometido a su tutela o guarda de hecho, será castigado con la pena de arresto mayor (artículo 425). La habitualidad se configuraba como el elemento esencial y diferenciador del tipo. El precepto carecía, sin embargo, de una definición o de un criterio interpretativo. Es por ello que, desde un primer momento, el núcleo de la discusión se centró en la delimitación de este concepto, llegándose incluso a abogar por su supresión (vid. enmiendas n. ${ }^{\circ} 5$ y n. ${ }^{\circ} 6$ del Grupo Parlamentario Mixto al Proyecto de Ley Orgánica de modificación del Código Penal de 1995, en materia de protección a las víctimas de malos tratos, y de la Ley de Enjuiciamiento Criminal, de 23 de febrero de 1999; Cortés Bechiarelli, 2000, p. 65).

El Código Penal de 1995 reprodujo, con ligeras modificaciones, su regulación en el artículo $153 \mathrm{CP}$. No será hasta la reforma operada por la LO 14/1999, de 9 de junio, cuando el legislador fije, al fin, unos

\footnotetext{
1 Artículo 153 CP: "El que habitualmente ejerza violencia física sobre su cónyuge o persona a la que se halle ligado de forma estable por análoga relación de afectividad o sobre los hijos propios o del cónyuge o conviviente, pupilos, ascendientes o incapaces que con él convivan o que se hallen sujetos a la potestad, tutela, curatela o guarda de
}

criterios interpretativos del término. Así, después de definir el delito, disponía en su apartado segundo que para la apreciación de la habitualidad se tendrá en cuenta el número de actos de violencia que resulten acreditados y también la proximidad temporal de estos, con independencia de que dicha violencia se haya ejercido sobre la misma persona o diferentes víctimas de las comprendidas en este artículo y que los actos violentos hayan sido o no objeto de enjuiciamiento en procesos anteriores. No se trataba, en efecto, de una definición de lo que ha de entenderse por habitualidad (de opinión contraria, Muñoz Conde, 2004, p. 189; Maqueda Abreu, 2001, p. 1520; Marín de Espinosa Ceballos, 2001, p. 222; Acale Sánchez, 1999, p. 111), sino que dicho precepto se limitaba a fijar las pautas que debían ser tomadas en consideración por el órgano judicial para apreciar su concurrencia (Olmedo Cardenete, 2004, p. 501 y 2001, p. 91; Muñoz Sánchez, 2004, p. 92). Se normativizaba, con ello, el concepto criminológico de habitualidad (Acale Sánchez, 1999, p. 66). Esta previsión fue recogida, de forma literal, en el apartado tercero del artículo 173 que, desde la reforma de la LO 11/2003, de 29 de septiembre, recoge el tipo penal del delito de maltrato habitual ${ }^{2}$, siendo la que permanece en la actualidad.

hecho de uno u otro, será castigado con la pena de prisión de seis meses a tres años, sin perjuicio de las penas que pudieran corresponder por el resultado que, en cada caso, se causare".

2 Artículo 173.3 CP: "Para apreciar la habitualidad a que se refiere el apartado anterior, se atenderá al número de actos de violencia que resulten acreditados, así como a la proximidad temporal de los mismos, con independencia de que dicha violencia se haya ejercido sobre la misma o diferentes víc- 
Pues bien, el presente trabajo tiene por objeto el estudio de los criterios que sirven, en el marco de la violencia de género, para delimitar la habitualidad, en tanto que elemento definidor del delito de maltrato habitual. En primer lugar, se determinarán las pautas dadas por el legislador para concretar los supuestos en que concurre la habitualidad, poniendo de relieve su carácter de conceptos jurídicos indeterminados. Se procederá, seguidamente, al análisis individualizado de cada uno de los elementos a efectos de aportar los criterios materiales con los que dar contenido a cada uno de esos requisitos. Posteriormente, se referenciarán los medios de prueba que sirven para acreditar la habitualidad. Finalmente, se presentarán las conclusiones a las que se llegó tras el estudio realizado

\section{METODOLOGÍA}

En la realización de nuestro estudio hemos tomado en consideración las siguientes fuentes: a) el análisis de los estudios doctrinales sobre el delito de maltrato habitual; b) el examen de la jurisprudencia dictada por el Tribunal Supremo en el marco del tipo delictivo objeto de estudio; c) los datos empíricos extraídos de los expedientes de la Fiscalía de Santiago de Compostela (Galicia, España), relativos al delito de maltrato habitual que concluyeron con sentencia firme durante los años 2005 a 2012 (en total, 102 casos).

timas de las comprendidas en este artículo, y de que los actos violentos hayan sido o no objeto de enjuiciamiento en procesos anteriores".
Ello representa el $17,59 \%(n=102)$ de las sentencias condenatorias por delitos de violencia de género dictadas en el área judicial de Santiago de Compostela en el período objeto de estudio (figura 1). Los datos obtenidos fueron incorporados a una base de datos elaborada ad hoc (Microsoft Office Excel 2007 ${ }^{\circledR}$ ). A partir de esta base se realizó un análisis estadístico descriptivo de los datos para lo que se usó el software R (R Core Team 2014).

\section{LOS ELEMENTOS DEFINITORIOS DE LA HABITUALIDAD}

Los estudios y aproximaciones realizados hasta la fecha se muestran críticos con la fórmula empleada por el legislador para la concreción del concepto de habitualidad. Se destaca, a este respecto, su vaguedad e imprecisión que lleva a que, en último término, sea la jurisprudencia, en vez del legislador, la encargada de delimitar su contenido (Falcón Caro \& Polaino Navarrete, 2001, p. 129).

Los criterios legales a tener en cuenta para constatar la habitualidad se vertebran alrededor de cuatro datos, que pasamos seguidamente a analizar: el número de actos de violencia que resulten acreditados; la proximidad temporal entre los actos violentos; la variedad de sujetos pasivos del delito: independencia de que los actos de violencia se hayan ejercido sobre la misma persona o cualquier otra de las comprendidas en el párrafo primero del precepto, y la independencia del enjuiciamiento o no de las conductas anteriores. 


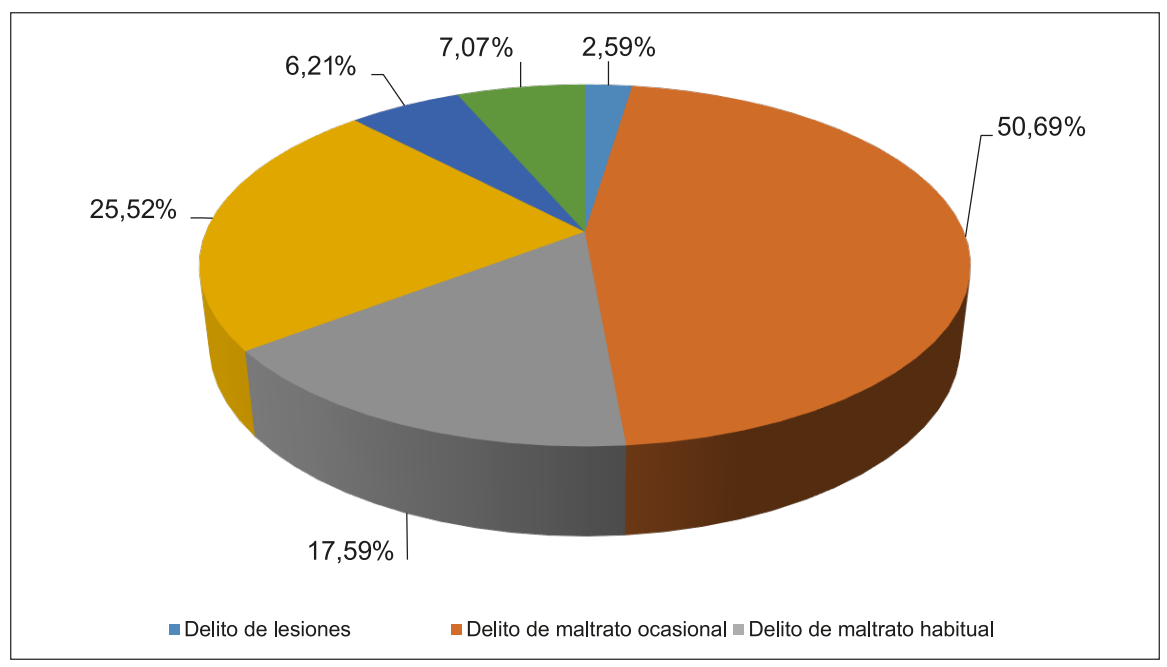

Figura 1. Tipos delictivos

Fuente: elaboración propia

\subsection{Número de actos de violencia que resulten acreditados}

Para la apreciación de la habitualidad el órgano judicial deberá tomar en consideración, en primer lugar, el número de actos de violencia-física o psíquica-que, teniendo relevancia penal (González Rus, 2004, p. 82; García Álvarez \& Del Carpio Delgado, 2000, p. 77), resulten acreditados. El legislador español se ha inclinado por un concepto abierto de habitualidad, no concretando los actos violentos necesarios para configurar el tipo penal (Marín de Espinosa Ceballos, 2001, p. 230). Esta falta de delimitación ha dado lugar al surgimiento de dos líneas interpretativas: una interpretación formal -caracterizada por su garantismo- y una interpretación material -caracterizada por su flexibilidad-.

La interpretación formal o criterio aritmético (concepto jurídico-formal) abo- gaba por concretar y cuantificar tanto el número de agresiones como el espacio temporal en el que estas debían producirse para poder apreciar la habitualidad. Con ello se perseguía dotar al término de seguridad jurídica y evitar, de este modo, situaciones de desigualdad en su aplicación (Benítez Jiménez, 2008, p. 186; Mayordomo Rodrigo, 2003, p. 93; García Álvarez \& Del Carpio Delgado, 2000, p. 65). El origen de esta interpretación parece hallarse en el artículo 428 CP/1948 en que se exigía, para la apreciación del tipo agravado de hurto habitual, la comisión de tres o más hurtos en un intervalo mínimo de veinticuatro horas entre cada uno de ellos (González Rus, 2004, p. 83). A partir de ahí se observa una tendencia doctrinal y jurisprudencial consistente en asociar el concepto de habitualidad con la comisión de un mínimo de tres actos violentos. A tales efectos, se llegó a apelar, para justificar de forma analógica 
tal exigencia, a la previsión contemplada en el artículo 94 CP en que se conceptúa como reos habituales a aquellos que "hubieren cometido tres o más delitos de los comprendidos en un mismo capítulo [...]". Esta interpretación fue asumida por los órganos judiciales (SSTS núm. 752/2004, de 7 junio; núm. 662/2002 de 18 abril; núm. 731/1999, de 6 de mayo), la Fiscalía General del Estado (Circular 1/1998, de 24 de octubre), la doctrina (Campos Cristóbal, 2002, p. 145; García Álvarez E Del Carpio Delgado, 2000, pp. 66-67; Cortés Bechiarelli, 2000, p. 75; Arroyo de las Heras \& Muñoz Cuesta, 1993, pp. 144-145) y el propio legislador. Prueba de esto último es que en el proyecto de Ley Orgánica de Código Penal de 1992 se preveía en su artículo 161 que la concurrencia de la habitualidad se apreciaría cuando el culpable hubiere sido condenado por tres o más delitos o faltas de lesiones. En esta misma línea apuntaba la enmienda formulada por el grupo parlamentario federal de Izquierda Unida -enmienda núm. 14- a la LO 14/1999, de 9 de junio, conforme a la que la habitualidad solo tendría lugar cuando dos o más actos de violencia resultasen acreditados.

Una segunda línea interpretativa, la línea material (concepto criminológico-social), abogaba, por el contrario, por prescindir de ese automatismo numérico al entender que lo relevante para apreciar la habitualidad, más que la pluralidad en sí misma, es que la repetición o frecuencia de los actos violentos sea de una entidad que permita al órgano judicial llegar a la convicción de que la víctima vive en un estado de agresión permanente. En este sentido, como acertadamente apunta Núñez Castaño (2010, p. 131; 2009, p. 36; 2002, p. 121)
[...] el comportamiento realmente prohibido es aquel que sea idó- neo para vulnerar el bien jurídico que se protege, tal como hemos señalado, la integridad moral, y este bien jurídico no se lesio- na por la mera suma de actos violentos concretos, sino por la creación de un clima de violen- cia y angustia provocado por esa reiteración, que desemboca en un sentimiento de miedo, humi- llación e inferioridad de la o las víctimas del mismo.

Esta segunda corriente preconizada desde la regulación inicial del tipo delictivo por, entre otros, Cuenca García (1991, p. 1186), Cuello Contreras (1993, p. 11), Del Rosal Blasco (1992, p. 373) y Ruiz Vadillo (1998, p. 3) es la que impera actualmente (entre otras, SSTS núm. 232/2015, de 20 de abril; núm. 856/2014, de 26 de diciembre; núm. 981/2013, de 23 de diciembre; núm. 701/2013, de 30 de septiembre; núm. 526/2012, de 26 de junio; núm. 765/2011, de 19 de julio; núm. 474/2010, de 15 de mayo; núm. 33/2010, de 3 de febrero; núm. 1151/2009, de 19 de noviembre núm. 607/2008, de 3 de octubre; núm. 1212/2006, de 25 de octubre; núm. 1909/2006 de 12 septiembre; núm. 613/2006, de 1 de junio; núm. 580/2006, de 23 de mayo; núm. 409/2006, de 13 abril núm. 181/2006, de 22 de febrero; núm. 1159/2005, de 10 de octubre; núm. 108/2005, de 31 de enero; núm. 752/2004 de 7 junio; núm. 1750/2003, de 18 de diciembre; núm. 907/2002, de 16 mayo; 
núm. 61/2001, de 2 de octubre; núm. 1208/2000, de 7 de julio; núm. 1366/2000, de 7 de septiembre; núm. 1208/2000, de 7 de julio; núm. 927/2000, de 24 de junio). El número de actos violentos concretos perpetrados ya no es más, por tanto, un criterio constitutivo de la habitualidad, sino un mero indicador de esta. Ello exige que para su apreciación se tomen en consideración otros aspectos tales como la situación, el contexto y la persistencia del clima enrarecido de convivencia generado por los episodios de violencia reiterados que lleven al órgano judicial al convencimiento de que la víctima vive en un estado de agresión permanente. En todo caso, el análisis de los expedientes por maltrato habitual revela que la media de actos violentos sufridos por las víctimas ascendió a 2.79 .

\subsection{Proximidad temporal entre los actos violentos}

El segundo de los elementos que deben concurrir para la apreciación de la habitualidad es la proximidad temporal entre los distintos actos violentos. Esta exigencia tiene por finalidad corroborar el carácter permanente y continuo de la situación de violencia en que se desarrolla la relación. La jurisprudencia aprecia la concurrencia de esa proximidad cronológica siempre que existan agresiones cercanas (STS núm. 1161/2000, de 26 de junio). La cuestión que se plantea seguidamente es el lapso temporal que puede existir como máximo entre las diversas agresiones a través de las que se pretende acreditar la habitualidad para considerar que persiste la proximidad temporal requerida. La casuística a este respecto es variada -e incluso contradictoria- sin que el legislador ni el Alto Tribunal hayan abordado todavía, de forma expresa, esta cuestión (valorando positivamente la ausencia de una previsión legal a este respecto, Marín de Espinosa Ceballos, 2001, p. 230; Acale Sánchez, 1999, p. 113; en contra Benítez Jiménez, 2008, p. 187; Falcón Caro \& Polaino Navarrete, 2001, p. 129). Así, en algunos casos se asume la proximidad con relación a aquellos hechos que ocurran en un determinado intervalo de 8 días (STS núm. 97/2003, de 28 febrero) en tanto que en otros este marco temporal puede abarcar un mes (SAP de Zaragoza, núm. 453/2000, de 26 octubre), dos meses (STS núm. 409/2006 de 13 abril), tres meses (SAP de Ourense núm. 16/2000, de 9 noviembre), seis meses (SAP de Pontevedra núm. 47/2009, de 27 de febrero), un año (STS núm. 1909/2006, de 12 septiembre) o tres años (SAP de Córdoba núm. 25/1999, de 21 abril). Contrasta a este respecto la SAP de A Coruña núm. 132/1997, de 19 noviembre, en la que se acuerda la absolución del procesado por estimar que existe una desconexión temporal entre los actos violentos sufridos al mediar entre el primero y el último de ellos 1 año y 3 meses.

Analizados los datos extraídos de los expedientes de la Fiscalía de Santiago de Compostela concluimos que, con carácter general, el hecho de que los episodios violentos se espacien en un período superior al de los tres años resulta difícilmente compatible con la exigencia de la habitualidad del maltrato. Corresponderá, en todo caso, al órgano judicial determinar, en cada supuesto concreto, 
si el lapso temporal entre unas y otras agresiones permite hablar de la existencia de un clima de terror o si, por el contrario, dichos periodos de "paz" hacen decaer tal ambiente familiar.

Esta circunstancia no se apreciará, en modo alguno, cuando la pluralidad de agresiones tenga lugar en único acto de violencia acaecido en un mismo contexto temporal (conclusiones aprobadas en la primera reunión de fiscales encargados de los servicios de violencia familiar celebrada en Madrid los días 27 a 29 de marzo de 2000; Del Moral García, 2004, p. 483; Martín de Espinosa Ceballos, 2001, p. 234; Olmedo Cardenete, 2001, p. 94; Moreno Verdejo, 2000, p. 374; Acale Sánchez, 1999, p. 141; en contra Falcón Caro E Polaino Navarrete, 2001, p. 129).

\subsection{Concurrencia de diferentes sujetos pasivos}

Un tercer elemento a tener en cuenta para apreciar la concurrencia de la habitualidad es la pluralidad de sujetos sobre los que pueden recaer los actos de violencia. Hasta la reforma operada por la LO 14/1999, de 9 de junio, fue objeto de discusión por la doctrina si la pluralidad de actos de violencia cuya comisión es necesaria a efectos de apreciar la habitualidad debían ser ejercidos sobre un mismo sujeto o si, por el contrario, podrían tomarse en consideración globalmente los actos de violencia sufridos por los demás sujetos pasivos del tipo.

Dicha posibilidad fue inicialmente rechazada por la Fiscalía General del Estado en su circular 2/1990, modificando su criterio, posteriormente, en su Circular 1/1998 afirmando que sí cabría sumar los actos violentos que recaigan sobre diferentes miembros de la familia siempre que, por un lado, aquellos convivieran en el mismo domicilio familiar y, además, de ello se derivase un clima de violencia que perturbase el desarrollo de los diferentes integrantes del núcleo familiar.

La actual redacción del artículo 173.3 CP deja ya claro, sin embargo, que la apreciación de la habitualidad tiene lugar con independencia de que dicha violencia se haya ejercido sobre la misma o diferentes víctimas de las comprendidas en el artículo $173.2 \mathrm{CP}$.

Los datos de nuestra investigación muestran cómo la violencia fue ejercida, en el $80.39 \%$ de los casos $(n=82)$, sobre el mismo sujeto -la cónyuge del autor-. Los demás actos violentos tienen como sujetos pasivos a los menores que conviven con la pareja $(16.67 \%, n=17)$ [Fig. 2].

En efecto, la habitualidad puede construirse a partir de actos de violencia ejercidos sobre distintos sujetos pasivos. Ahora bien, teniendo en cuenta el bien jurídico protegido por el delito - la paz familiar-, es preciso que aquellos se hallen integrados en el mismo marco convivencial (Del Moral García, 2004, p. 486 y 2000, p. 327; Circular FGE 1/1998; en contra Aránguez Sánchez, 2002, pp. 218-219). Si los actos de violencia ejercidos sobre esa pluralidad de víctimas pueden, considerados de forma separada, conformar el tipo delictivo, se apreciarán, en concurso real, 


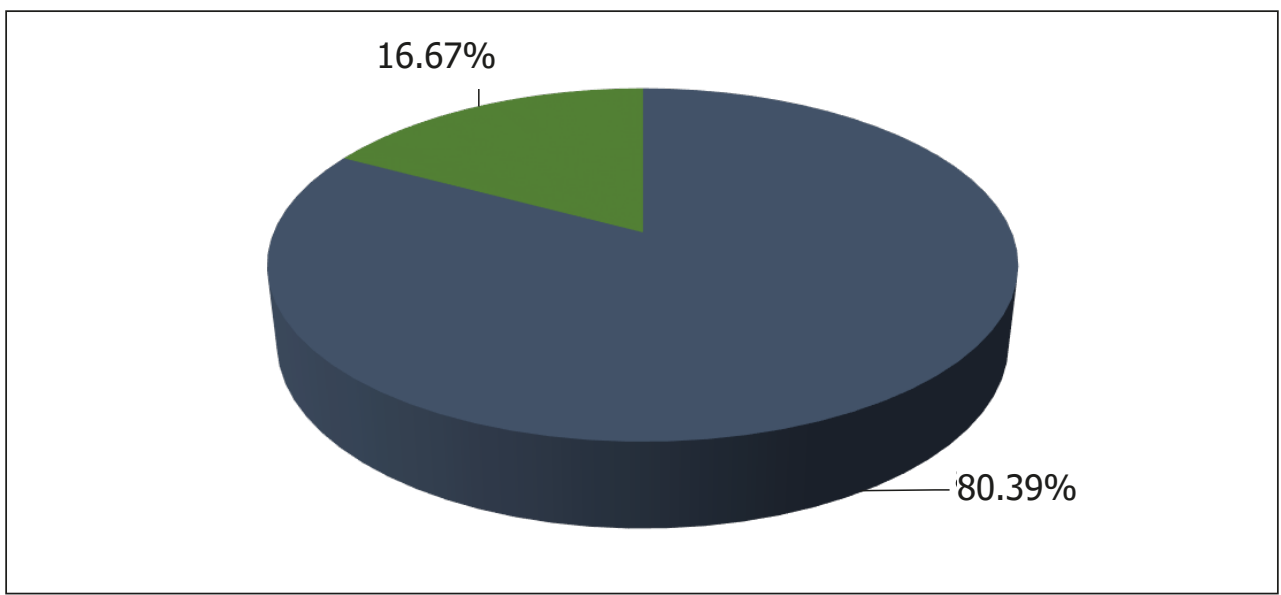

Figura 2. Sujetos pasivos de los actos violentos Fuente: elaboración propia

tantos delitos de maltrato habitual como víctimas existan (García Álvarez \& Del Carpio Delgado, 2000, pp. 73-74).

\subsection{Independencia del enjuiciamiento o no de los actos violentos en procesos anteriores}

Con arreglo a lo dispuesto en el artículo $173.3 \mathrm{CP}$, para la apreciación de la habitualidad es indiferente que los actos violentos que integren el delito de maltrato habitual hayan sido objeto de enjuiciamiento en procesos anteriores. Esta previsión representa uno de los cambios más relevantes en la forma de acreditación de la habitualidad (Marín de Espinosa Ceballos, 2001, p. 237). Hasta la reforma operada por la LO 14/1999, de 9 de junio, la imposibilidad de tomar en consideración los hechos ya juzgados, por entenderse que en caso contrario se estaría vulnerando el principio ne bis idem, dificultaba sobremanera su apreciación, convirtiéndolo en un precepto prácticamente inaplicable.
La Circular 1/1998 de la Fiscalía General del Estado estimaba, por el contario, que este principio no se vería conculcado en la medida en que el bien jurídico tutelado en el delito de maltrato habitual -integridad moral de la víctima- es diferente del protegido en cada una de las acciones violentas que integran el tipo -integridad física o psíquica de la víctima- (Olaizola Nogales, 2010, p. 290). El valor de estos actos se limita, en esencia, a acreditar la actitud del agresor (STS núm. 1356/2001, de 9 de julio). La doctrina se inclina, no obstante, por la opción de que la acreditación de la habitualidad no se fundamente, en exclusiva, en acciones aisladas que ya hubieran sido objeto de condena, por más que ello sea conforme al tenor literal de la norma (Lorenzo Salgado, 2015, p. 203). En todo caso, los actos de violencia que ya hayan sido tomados en consideración para fundamentar una condena por delito de maltrato habitual no podrán ser tomados nuevamente en consideración a estos efectos. Para que se produzca una 
nueva condena por violencia habitual es preciso que se acrediten nuevos hechos, posteriores a aquellos que demuestren la reiteración del comportamiento delictivo (STS 105/2007, de 14 de febrero).

Mayores problemas plantea la toma en consideración de aquellos actos violentos respecto de los que se haya dictado una sentencia absolutoria. Desde una posición mayoritaria se estima que dichos hechos no podrán ser valorados a efectos de integrar el concepto de habitualidad al predicarse respecto de estos la excepción de cosa juzgada (SSTS núm. 66/2013, de 25 de enero; núm. 805/2003, de 18 de junio; núm. 687/2002, de 16 abril). Con gran claridad expone la SAP de Valladolid núm. 245/2001, de 31 marzo que "la dicción del párrafo segundo del artículo 153 del CP (actual artículo 173.2 CP), de hechos que hayan sido ya juzgados, para acumularlos a otros, a los efectos de la habitualidad, deben entenderse en el sentido de aquellos hechos, que juzgados, hayan sido objeto de sentencia condenatoria firme". De otra opinión es Moreno Verdejo (2000, p. 381) para quien "la absolución o el sobreseimiento libre por un concreto resultado lesivo impedirá que pueda volver a enjuiciarse tal hecho para su castigo -se afirma la eficacia negativa de la cosa juzgada-, pero no que ese acto lesivo pueda ser tenido en consideración únicamente a efectos de integrar el clima de violencia o habitualidad para una ulterior condena por el artículo 153 -se niega la eficacia positiva de cosa juzgada-" (en la misma línea, Aránguez Sánchez, 2002, p. 236; Del Moral García, 2000, pp. 231-234; Conclusiones aprobadas en la primera reunión de fiscales encargados de los servicios de violencia familiar celebrada en Madrid los días 27 a 29 de marzo de 2000). El efecto de cosa juzgada no se predica, por el contrario, respecto de aquellos hechos con relación a los que haya recaído un auto de archivo o de sobreseimiento provisional (STS núm. 1016/2005, de 12 de septiembre).

Finalmente, y por lo que respecta a la posible prescripción de los actos violentos, una cosa es que pueda aplicarse el instituto de la prescripción a determinados hechos constitutivos de delito y otra, muy distinta, que esos hechos y acciones no puedan tener la consideración de pruebas demostrativas de la habitualidad en las acciones maltratadoras (STS núm. 592/2004, de 3 de mayo). En todo caso, conforme a lo preceptuado en el artículo 132.1 CP, en virtud de la reforma operada por la LO 15/2003, el comienzo de la prescripción de las infracciones que exijan habitualidad se computará desde que cese la conducta.

\section{LOS MEDIOS DE PRUEBA DE LA HABITUALIDAD}

El respeto al principio de presunción de inocencia exige que la habitualidad sea probada. Para ello deben acreditarse, de forma fehaciente, cada uno de los actos violentos que han tenido lugar. Ello puede efectuarse desde una triple perspectiva (STS núm. 1309/2005, de 11 noviembre):

a) Acreditación judicial: no solo las condenas previas por delitos de violencia de género pueden operar como elemento acreditativo, sino también las 
denuncias interpuestas por la víctima, cualquiera que haya sido el destino de esas diligencias. No son estas, sin embargo, las principales formas de acreditación de la habitualidad. Así, la condena anterior del agresor por actos de violencia de género solo ha servido para acreditar el 1.63\% $(n=2)$ de los actos de violencia física y el $1.83 \%(n=2)$ de los actos de violencia psíquica. Por su parte, la denuncia de la víctima ha atestiguado el $11.38 \%$ ( $n=14)$ de los actos de violencia física y el $11.93 \%(n=13)$ de los de violencia psíquica (figuras. 3 y 4).

b) Acreditación médica: los partes de lesiones pueden servir para acreditar tanto las diversas agresiones sufridas por la víctima -hayan dado lugar o no a la incoación de diligencias- como la proximidad temporal en que estas se han sufrido. De acuerdo con los datos de nuestro estudio, los partes de lesio- nes se han utilizado para documentar el $11.38 \%(n=14)$ los actos de violencia física y el $1.83 \%(n=2)$ los actos de violencia psíquica (figuras 3 y 4).

c) Acreditación testifical: la declaración de la víctima, de familiares, de vecinos, entre otros, puede ofrecer al órgano judicial datos suficientes para que llegue a la convicción de que, con independencia de la agresión que motiva las diligencias, ha habido otras semejantes en tiempos cercanos. La acreditación testifical por la víctima ha tenido una notable repercusión en la prueba de la habitualidad. Conforme a los resultados derivados de nuestro estudio estas últimas han sido el principal elemento acreditativo de la habitualidad, tanto en relación con los actos de violencia física como con los de violencia psíquica (un 53.66\%, $n=66$ y un $51.38 \%, n=56$, respectivamente) [figuras 3 y 4 ].

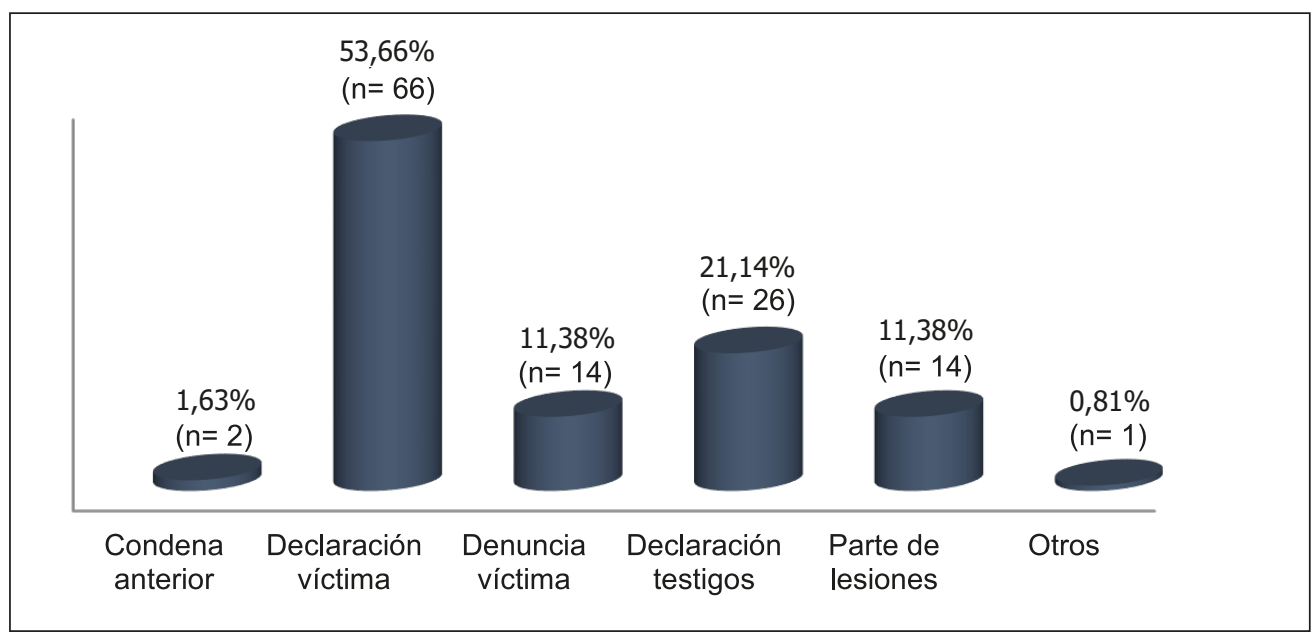

Figura 3. Formas de acreditación de la violencia física

Fuente: elaboración propia 


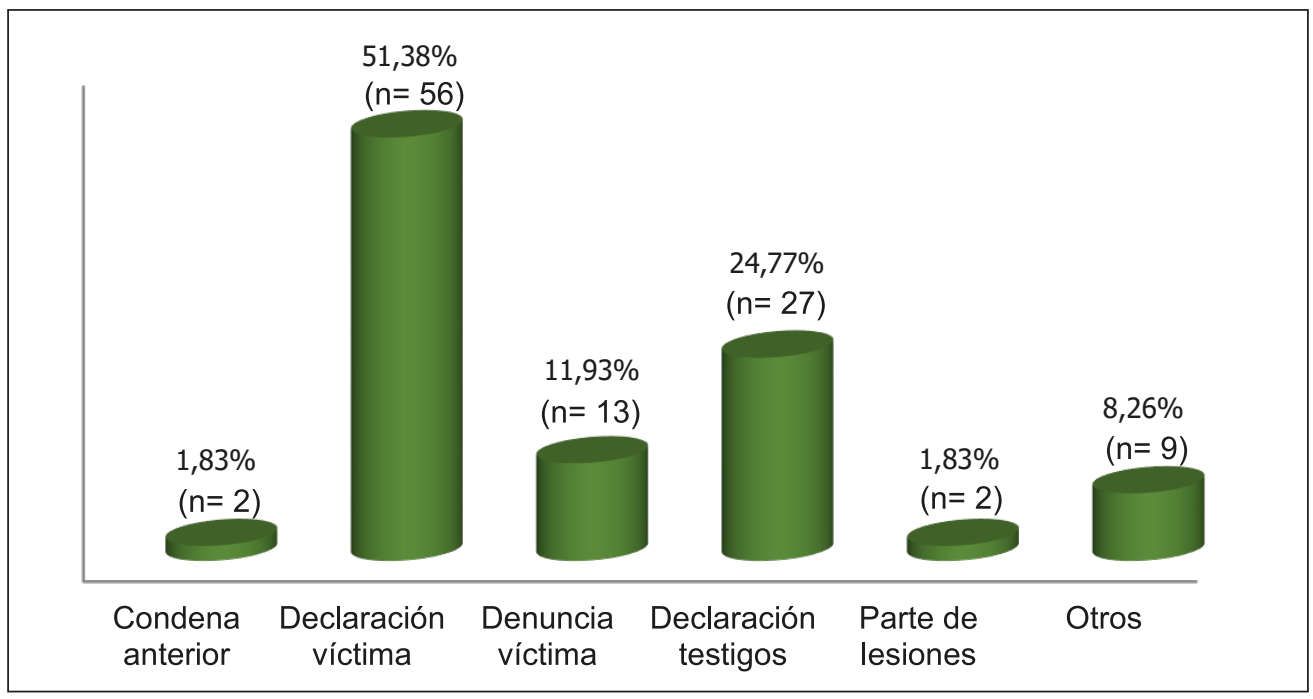

Figura 4. Forma de acreditación de la violencia psíquica

Fuente: elaboración propia

\section{CONCLUSIONES}

De lo expuesto en este trabajo, se pueden extraer las siguientes conclusiones:

La habitualidad se configura como el elemento esencial y diferenciador del delito de maltrato habitual. No obstante, el Código Penal español no contiene una definición de lo que debe de entenderse por habitualidad en el marco del delito de maltrato habitual. El legislador se limitó a fijar las pautas que debían ser tomadas en consideración por el órgano judicial para apreciar su concurrencia.

La apreciación de la habitualidad exige, actualmente, que la repetición o frecuencia de los actos violentos -físicos o psicológicos- perpetrados sean de una entidad suficiente para que el órgano judicial pueda llegar a la convicción de que la víctima vive en un estado de agresión permanente, con independencia del número de agresiones sufridas.

La habitualidad puede construirse a partir de actos de violencia ejercidos sobre los distintos sujetos pasivos del delito de maltrato habitual. Ahora bien, teniendo en cuenta el bien jurídico protegido por el derecho -la "paz familiar"-, es preciso que aquellos se hallen integrados en el mismo marco de convivencia.

La casuística en cuanto al requisito de la cercanía de las agresiones es variada -e incluso contradictoria-, si bien es cierto que más allá del marco temporal de los tres años entre una y otras ocasiones no suele apreciarse la concurrencia de la habitualidad.

Para la apreciación de la habitualidad es indiferente que los actos violentos que 
integren el delito de maltrato habitual hayan sido objeto de enjuiciamiento en procesos anteriores. Ello no vulnera el principio ne bis in idem en la medida en que el bien jurídico tutelado en el delito de maltrato habitual -integridad moral de la víctima- es diferente del protegido en cada una de las acciones violentas que integran el tipo -integridad física o psíquica de la víctima-.

Tratándose de actos violentos respecto de los que se haya dictado una sentencia absolutoria, no podrán ser valorados a efectos de integrar el concepto de habitualidad al predicarse respecto de estos la excepción de cosa juzgada. En cuanto a la toma en consideración de los actos ya prescritos, una cosa es que pueda aplicarse el instituto de la prescripción a determinados hechos constitutivos de delito y otra, muy distinta, que esos hechos y acciones no puedan tener la consideración de pruebas demostrativas de la habitualidad en las acciones maltratadoras.

La acreditación testifical por parte de la víctima se revela como el principal elemento de prueba de la habitualidad, tanto en relación con los actos de violencia física como con los de violencia psíquica.

\section{REFERENCIAS BIBLIOGRÁFICAS}

Acale Sánchez, M. (1999). El delito de malos tratos físicos y psíquicos en el ámbito familiar. Valencia: Tirant lo Blanch.

Aránguez Sánchez, C. (2002). "El concepto de habitualidad en el delito de violencia doméstica". En L. Morillas Cueva (coord.). Estudios penales sobre violencia doméstica (pp. 197-238). Madrid: Edersa.

Arroyo de las Heras, A. E Muñoz Cuesta, J. (1993). Delito de lesiones. Pamplona: Aranzadi.

Benítez Jiménez, Mª J. (2008). "Las violencias habituales en el ámbito familiar: artículo 173.2 del Código Penal". En C. Villacampa Estiarte (coord.). Violencia de género y sistema de justicia penal (pp. 163-216). Valencia: Tirant lo Blanch.

Campos Cristóbal, R. (2002). La habitualidad en el delito de violencia habituales en el ámbito familiar. Estudios Penales y Criminológicos, (24), pp. 128-186.

Cortés Bechiarelli, E. (2000). El Delito de malos tratos familiares: nueva regulación. Madrid: Marcial Pons.

Cuello Contreras, J. (1993). "El delito de violencia habitual en el seno de la familia y otras relaciones análogas de afectividad". Revista del Poder Judicial, (32), pp. 9-18.

Cuenca Sánchez, J.C. (1991). "El nuevo artículo 425 del Código penal. Dificultades de aplicación". La ley, (4), pp. 1184-1189.

Del Moral García, A. (2004). "Aspectos penales de la violencia doméstica. La actuación del Ministerio Fiscal". En AA.VV. Encuentros "violencia doméstica" (pp. 457-526). Madrid: CGPJ.

(2000). "La habitualidad como elemento típico del delito del artículo 153 del Código Penal: problemas concursales y procesales". En AA.VV. Estudios sobre violencia familiar y agresiones sexuales (pp. 227-240). Madrid: Ministerio de Justicia.

Del Rosal Blasco, B. (1992). "El tipo de violencias en el ámbito familiar o tutelar". En AA.VV. Comentarios a la legislación penal (pp. 369280). Madrid: Edersa.

Falcón Caro, M. ${ }^{\text {a }}$ C. E Polaino Navarrete, M. (2001). Malos tratos habituales a la mujer. Barcelona: J.M Bosch. 
García Álvarez, P. E Del Carpio Delgado, J. (2000). El delito de malos tratos en el ámbito familiar: (LO 14/1999, de 9 de junio): problemas fundamentales. Valencia: Tirant lo Blanch.

Lorenzo Salgado, José Manuel (2015): "El delito de violencia habitual en el ámbito doméstico y asimilado". En Vázquez-Portomeñe Seijas, Fernando (dir.): Violencia contra la mujer. Manual de derecho penal y procesal. Madrid: Ed. Tirant lo Blanch, 2015, pp. 181-216.

Maqueda Abreu, M. ${ }^{a}$. L. (2001), "La violencia habitual en el ámbito familiar: razones de una reforma". En G. Quintero Olivares \& F. Morales Prats (coords.). El nuevo Derecho penal español. Estudios penales en memoria del profesor José Manuel Valle Muñiz (pp. 1515-1540). Navarra: Aranzadi.

Marín de Espinosa Ceballos, E. (2001). La violencia doméstica. Análisis sociológico, dogmático y de derecho comparado. Granada: Comares.

Mayordomo Rodrigo, V. (2003). Aspectos criminológicos, victimológicos y jurídicos de los malos tratos en el ámbito familiar: Bilbao: Servicio Editorial de la Universidad del País Vasco.

Moreno Verdejo, J. (2000). "El concepto de habitualidad en el delito del artículo 153 del Código Penal: aspectos procesales y sustantivos". En AA.VV. Estudios sobre violencia familiar y agresiones sexuales (pp. 361-382). Madrid: Ministerio de Justicia.
Muñoz Sánchez, J. (2006). "El delito de violencia doméstica habitual. Artículo 173.2 del código penal". En M.A. Boldova Pasamar E M.A. Rueda Martín (coords). La reforma penal en torno a la violencia doméstica y de género (pp. 69100). Barcelona: Atelier.

Nuñez Castaño, E. (2010). "La violencia doméstica en la legislación española: especial referencia al delito de maltrato habitual (artículo 173.2 del Código Penal)". En Revista de Estudios de la Justicia, (12), pp. 97-148.

(2009). "El delito de maltrato habitual: entre la violencia de género y la violencia doméstica". En Revista General de Derecho Penal, pp. 1-55.

(2002). El delito de malos tratos en el ámbito familiar: aspectos fundamentales de la tipicidad. Valencia: Tirant lo Blanch.

Olaizola Nogales, I. (2010). Violencia de género: elementos de los tipos penales con mayor dificultad probatoria. Estudios Penales y Criminológicos, (30), pp. 269-316.

Olmedo Cardenete, M. (2001). El delito de violencia habitual en el ámbito doméstica: análisis teórico y jurisprudencial. Barcelona: Atelier.

Ruiz Vadillo, E. (1998). "Las violencias físicas en el hogar". Actualidad Jurídica Aranzadi, (326), pp. 1-20. 